\title{
Increased use of analgesics in midlife women but no association with mental stress: observations from the Prospective Population Study of Women in Gothenburg
}

\author{
Dominique Hange ${ }^{1,2^{*}}$, Gunilla Fernlöf ${ }^{1}$, Cecilia Björkelund ${ }^{1}$ and Tove Hedenrud ${ }^{3}$
}

\begin{abstract}
Background: The study is part of the ongoing Prospective Population Study of Women in Gothenburg, Sweden, initiated in 1968-1969 with the aim of characterising a total population of women who were representative of middleaged females. The aim of the present study was to investigate the prevalence of actual analgesic use (prescribed and self-medication) and the possible association with perceived mental stress among women aged 38 and 50 years, respectively, in the Population Study of Women.
\end{abstract}

Methods: Two different cohorts of population-based samples of 38- and 50-year-old women examined in 20042005 and 2016-2017, respectively, were eligible participants. The women were representative for their age cohort at the time of the examinations. Use of medicines and especially analgesics, as well as perceived mental stress, was registered. Changes in medicine use among 38- and 50-year-old women between 2004 and 2005 and 38- and 50-year-old women in 2016-2017 were studied. Data were analysed using logistic regression. Use of analgesics and mental stress were analysed controlling for lifestyle factors, use of other medicines and pain.

Results: The overall sample size across the time periods was 1,073 individuals. The frequency of analgesic use in 38- and 50-year-old women was about 26\% in 2004-2005 and 58\% in 2016-2017. 28\% of women who reported high mental stress in 2004-2005 used analgesics, compared to 60\% in 2016-2017. There were no associations between self-perceived mental stress and the use of analgesics.

Conclusion: The higher use of analgesics among midlife women in 2016-2017 is in line with global findings and could be due to increased availability in Sweden of over the counter medicines. The impact of mental stress on analgesic use found previously by other researchers was not confirmed. However, medicine use as a potential coping strategy is an important public health issue that needs to be further explored.

Keywords: Analgesics, Mental stress, Non-steroidal anti-inflammatory medicine, Population study, Women

*Correspondence: dominique.hange@allmed.gu.se

1 Department of Public Health and Community Medicine/Primary Health Care, School of Public Health and Community Medicine, Institute of Medicine, Sahlgrenska Academy, University of Gothenburg, PO Box 454, 40530 Gothenburg, Sweden

Full list of author information is available at the end of the article

\section{Background}

Sales of analgesics are increasing worldwide, where the United States, China and Brazil are the top three countries (2020) with regard to revenue in the analgesic segments [1]. Analgesics have a prominent position within the context of self-medication, in line with the global trend where more and more medicines are being sold 
without prescription [2]. In Europe (2017), the sales of analgesic products bought over-the-counter (OTC) showed Italy as the market leader followed by Germany, with Sweden in seventh place [1]. An earlier international comparison showed that the highest per-capita consumption was observed in Sweden with 147 Standard Units per capita per year, an increasing trend from 1986 [3]. In Sweden, the availability of OTC analgesics has increased during the last decade due to a new reform allowing them to be sold in non-pharmacy outlets [4]. This reform also led to an increased number of pharmacies, which further increased the availability of OTC medicines. In a population-based study, about $10 \%(\mathrm{~N}=2594)$ reported a higher use of OTC medicines due to the increased availability [5]. In most countries, the prevalence of self-medicated analgesic use is higher in women than men [6]. Thus, a Danish population study found that $27 \%(\mathrm{~N}=22,199)$ of the women and $18 \%(\mathrm{~N}=23,080)$ of the men aged 18-45 years had a regular monthly use of analgesic tablets [7]. Similar gender differences have been seen in Sweden [8].

The main reason for using analgesics is pain and women generally have a higher prevalence of many pain disorders as well as chronic pain [9]. Self-perceived poor health can also explain much of analgesic use. Other important factors for analgesic use are sleeping problems and health care utilisation [10]. The use of analgesic has been shown to be higher among smokers, and obese adults with medium or high socio- economic status and lower in adults performing more than $2 \mathrm{~h}$ /week of physical exercise [11]. Patients with chronic pain can use alcohol together with opioids as treatment [12]. Pain severity has been shown to be the strongest independent predictor of sleep problems [13], which in turn can lead to higher use of analgesic.

Findings from the $90 \mathrm{~s}$ showed that the use of tranquilizers, hypnotics, and analgesics could be associated with stressors such as unemployment and conflicts with a spouse [14]. Koushede et al. could later show an association between mental stress and OTC analgesic use, both in men and women $25-44$ years old $(\mathrm{N}=4739)$ [15]. Using analgesics for emotional modulation/sedation have also been shown to have a strong association with greater distress and depression [16]. During the last decades an increase of perception of mental stress from around 25 to $75 \%$ has been registered in the female middle-aged population in Sweden [17]. There are suggestions that some medicine use may be a behaviour reflecting a general coping strategy to overcome daily stressors outside therapeutic indications [18]. This type of behaviour regarding medicine use is important to study, since it may lead to interactions with prescribed medicines and have an impact on health and well-being. The aim of the present study was to study secular trends of analgesic use and investigate the prevalence of actual analgesic use (prescribed and self-medication) and the possible association with perceived mental stress among women aged 38 and 50 years, respectively, in the Population Study of Women in 2004-2005 and 2016-2017.

\section{Methods}

This observational study uses data from two different cohorts of population-based samples of 38- and 50-yearold women, recruited in 2004-2005 and 2016-2017 from the Prospective Population Study of Women in Gothenburg, Sweden (PSWG) [19]. The present study used cross-sectional data from the two consecutive examinations for investigating the prevalence and secular trends of actual analgesic use (prescribed and self- medication) and the possible association with self-perceived mental stress in middle-aged women.

\section{Characteristics of participants}

In 1968-1969, 1462 women aged 38, 46, 50, 54 and 60 participated in the PSWG [19]. The selection of women was based on their date of birth to make the sample representative. After that, follow up examinations were conducted in 1974-1975, 1980-1981, 1992-1993, 2000 2001, 2004-2005, 2005-2006 and in 2016-2017. The participation rate has been high throughout all years, i.e., around $90 \%$ at the three first examinations and $70 \%$ in $1992-1993,71 \%$ in $2000-2001$ and $72 \%$ in $2005-2006$. Details of the sampling procedure and participation rates at earlier examinations have been presented elsewhere $[19,20]$. Physical examinations were conducted according to the same protocol at all examinations.

In 2004-2005 a new sample of 38- and 50-year-old women was invited, in which women born in 1966 were examined for the first time. Some of the women born in 1954 had participated in the 1992-1993 examination and the remaining were newly recruited to reach representativeness. A total of 343 women aged 38 and 503 aged 50 were invited to a free health examination. The sample was obtained from the Revenue Office Register, based on the womens' date of birth. The survey was performed over a six-month period. The women were contacted by post and followed up with a phone call, when the phone number was available. A total of 500 women (207 38-year-olds and 293 50-year-olds) accepted the invitation (73\% and $70 \%$, respectively of those reachable by telephone) [21] (Fig. 1).

In 2016-2017 women born in 1978 were examined for the first time, and a new group of women born in1966 was recruited to reach representativeness, the remainder having participated in 2004-2005. A total of 515 women aged 38 and 523 aged 50 were invited to a 


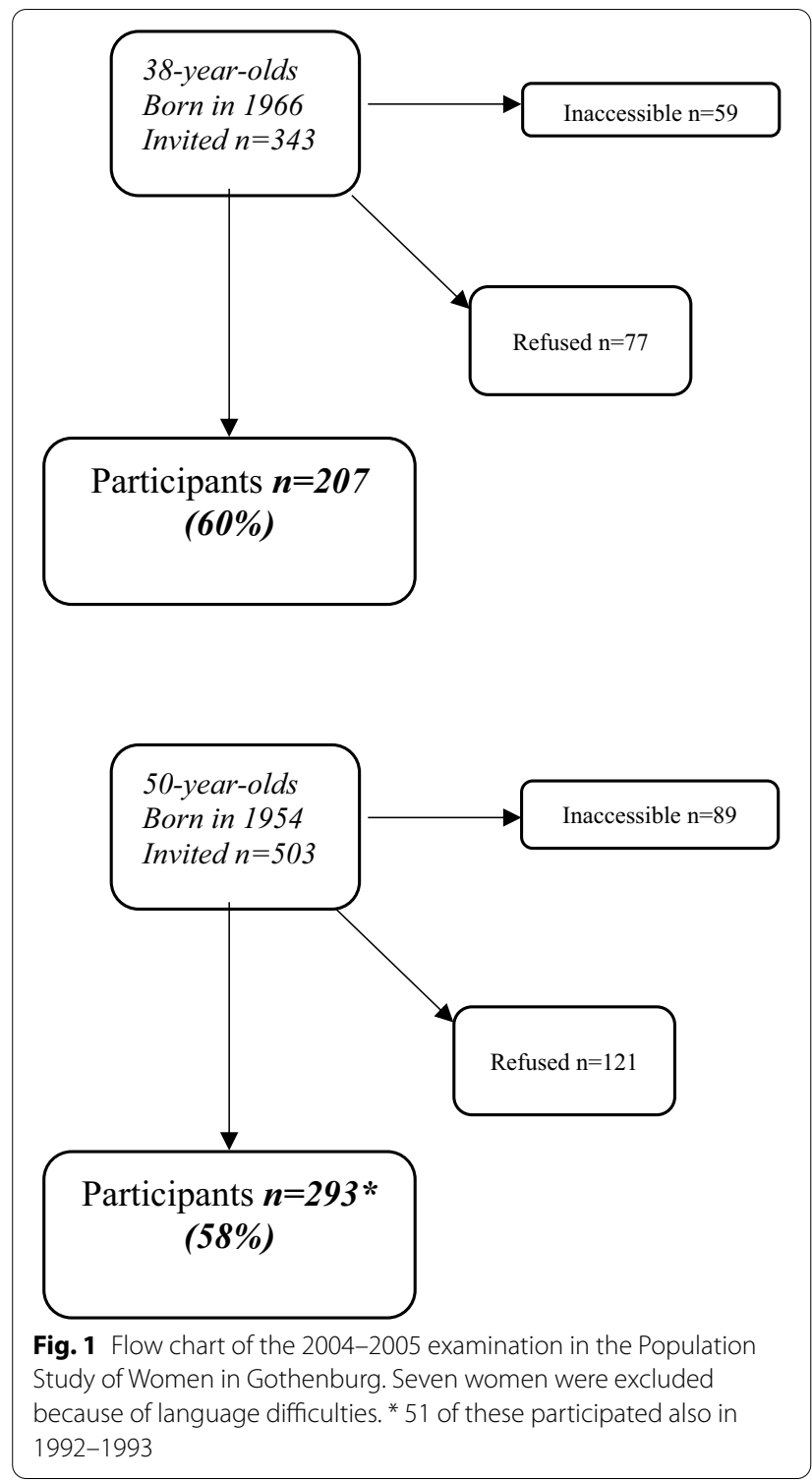

free health examination. The sample was obtained from the Revenue Office Register. The survey was performed over an 8-month period. Invitations were sent out by post and followed up with a phone call, when the phone number was available. A total of 573 women (263 38 -year-olds and 310 50-year-olds) accepted the invitation $(63 \%$ and $73 \%$ of those reachable per telephone, respectively) [22] (Fig. 2).

For the purpose of the present study, it was decided to increase power to detect differences between 20042005 and 2016-2017 cohorts by merging 38-year-olds and 50-year-olds into one group, respectively, in order to obtain a larger group of women at each time point,

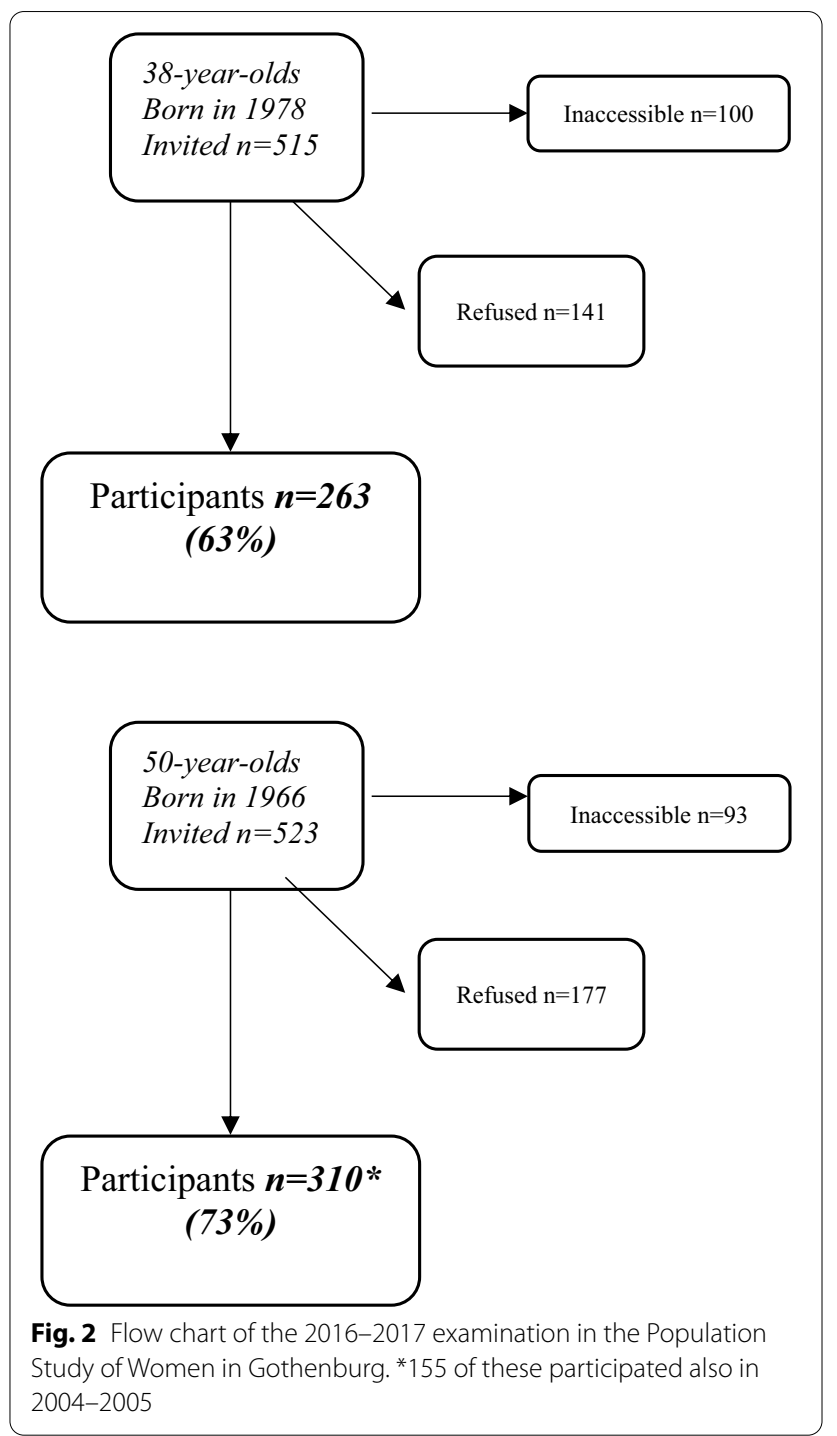

reaching the number of 500 women in 2004-2005 and 573 in 2016-2017.

Study population characteristics, i.e., social group, smoking, alcohol consumption, leisure time physical activity, and amount of sleep are shown in Table 1.

\section{Definition and identification of analgesic use}

This study focuses on anti-inflammatory and anti-rheumatic medicines (M01), analgesics (N02), opioids (N02A), other analgesics (N02B), salicylates (N02BA), paracetamol (NO2BE) and anti-migraine medicines (N02C). The dependent variable was use or no use of medicines within ATC (Anatomical Therapeutic Chemical) code [23], M01 and/or N02. The nurse noted on a standardised form the name of the product, the ATC code, strength, number of units and whether use was daily or when needed (prn). 
Table 1 Background characteristics of 38-and 50-year-old women in the Population Study of Women in Gothenburg

\begin{tabular}{|c|c|c|}
\hline & $\begin{array}{l}2004-2005 \\
\text { n (\%) }\end{array}$ & $\begin{array}{l}2016-2017 \\
\text { n (\%) }\end{array}$ \\
\hline \multicolumn{3}{|l|}{ Social group } \\
\hline Low & $134(26.8)$ & $102(17.8)$ \\
\hline Medium & $244(48.8)$ & $258(45.0)$ \\
\hline High & $105(21.0)$ & $192(33.5)$ \\
\hline Missing & $17(3.4)$ & $21(3.7)$ \\
\hline \multicolumn{3}{|l|}{ Education } \\
\hline Low & $232(46.4)$ & $190(33.2)$ \\
\hline High & $261(52.2)$ & $374(65.3)$ \\
\hline Missing & $7(1.4)$ & $9(1.6)$ \\
\hline \multicolumn{3}{|l|}{ Smoking } \\
\hline Currently & $90(18.0)$ & $60(10.5)$ \\
\hline Never/ever & $405(81.0)$ & $513(89.5)$ \\
\hline Missing & $5(1.0)$ & - \\
\hline \multicolumn{3}{|l|}{ Alcohol } \\
\hline Never & $39(7.8)$ & $86(15.0)$ \\
\hline Sometimes & $342(68.4)$ & $393(68.6)$ \\
\hline Regularly & $111(22.2)$ & $92(16.1)$ \\
\hline Missing & $8(1.6)$ & $2(0.3)$ \\
\hline \multicolumn{3}{|l|}{ Leisure time exercise } \\
\hline Less than $4 \mathrm{~h} /$ week & $94(18.8)$ & $49(8.6)$ \\
\hline At least $4 \mathrm{~h}$ /week & $399(79.8)$ & $522(91.1)$ \\
\hline Missing & $7(1.4)$ & $2(0.3)$ \\
\hline \multicolumn{3}{|l|}{ Amount of sleep } \\
\hline Not enough sleep & $213(42.6)$ & $259(45.2)$ \\
\hline Enough sleep & $279(55.8)$ & $306(53.4)$ \\
\hline Missing & $8(1.6)$ & $8(1.4)$ \\
\hline Total (n) & 500 & 573 \\
\hline
\end{tabular}

Other medicines that were included in the analysis were anti-acid medicines (A02), sedatives (N05C), hypnotics (N05B) and antidepressants (N06A). Both daily use and prn use were included. These were chosen as covariates due to their frequent use in relation to mental stress.

\section{Definitions of mental stress}

The prevalence of mental stress was based on a question describing the extent to which the women had experienced mental stress previously or presently. Participants were asked: "Have you experienced any period of mental stress (1 month or more), and with mental stress we mean that you have been irritable, tense, nervous, anxious, afraid, anguished or unable to sleep, connected with concern for your work, your health, your family or conflict with the people around you (at home, at work)?".

To describe the prevalence of mental stress, a model with three levels was used:
Mental stress level 0-1: no mental stress during the last 5 years, including the current period Mental stress level 2: occasionally experienced mental stress during the last 5 years Mental stress level 3-5: experienced constant or several periods of mental stress during the last 5 years.

The mental stress question was asked in exactly the same way at all follow ups. The question has been used in various epidemiological studies $[24,25]$ and has been found to be a valid measure of mental stress, compared to other psychometric instruments [26].

\section{Social group and education}

The women reported their occupations and total income status, and this information was used to classify their social group into three categories: high, medium, or low. The categorisation was based primarily on the husband's profession, secondly on the women's own profession, and was carried out in accordance with the Swedish socioeconomic index, that includes the number of years in an occupation in combination with educational level [27]. Low socioeconomic status designated skilled and unskilled workers, intermediate socioeconomic status small-scale employers, officials of lower rank and foreman, high socioeconomic status large-scale employers and officials of high or intermediate rank.

Based on the number of years reported by each woman, higher education was defined as education beyond elementary school (more than 6-7 years).

\section{Smoking}

Smoking habits was defined as whether the woman was a current smoker or not.

\section{Alcohol consumption}

Information regarding alcohol habits was obtained using a standardised structured interview conducted by a physician. All participants were asked to report the frequency of their consumption of three different types of alcoholic drinks, i.e., beer, wine, and spirits. Women were asked: "Do you use beer, wine, and/or spirits" and then to report the frequency according to the following alternatives: $0=$ Never; $1=$ Earlier, but not during the last 10 years; $2=$ Earlier, but not during the last year; $3=$ Monthly; $4=$ Weekly; $5=$ Several times a week; $6=$ Daily [28].

For the purpose of this study, we derived three separate categories of consumption of any alcohol, based on the various levels (frequency) were: never (including levels 0 , 1 and 2); sometimes (including levels 3 and 4); regularly (including levels 5 and 6). 


\section{Physical activity}

Leisure time physical activity (LTPA) was assessed in terms of 4 categories: 'almost inactive' (reading, watching TV, etc.), 'some physical activity at least $4 \mathrm{~h} /$ week' (cycling, walking, etc.), 'regular exercise' (tennis, running, heavy gardening, etc.), and 'regular training and competitive sports' [25]. Physical inactivity was defined as low LTPA, i.e., less than $4 \mathrm{~h}$ of LTPA per week versus more.

\section{Sleep quality}

The study question regarding sleep "Is your sleep long enough?" with the response alternatives: Yes or No.

\section{Pain experience}

A general question about pain experience was included in the study: "How much bodily pain have you had during the last 4 weeks?". The response alternatives were: None, very mild, mild, moderate, severe, very severe. For the purpose of this study the alternatives were classified into three categories; "none", "very mild and mild", and "moderate, severe and very severe".

\section{Data collection}

At the study clinic, a nurse inquired about current medicine use. Participants were asked the following: "Considering any medicine prescribed by a doctor or purchased without a prescription in a pharmacy-what are you currently using?".

\section{Statistical methods}

Background characteristics and frequency of analgesic use were analysed as proportions for each study year (2004-2005 and 2016-2017). Proportion of analgesic users for each study year was analysed in relation to level of perceived mental stress.

Logistic regression analysis was performed for each study year where analgesic use was the dependent variable. Perceived mental stress, together with age and social group, was entered in the first model. In the second model, the covariates of pain and other medicines were added. Finally, in the third model, lifestyle covariates were added. Associations were reported as odds ratios (OR) with $95 \%$ confidence intervals $(\mathrm{CI})$. All analyses were performed with SPSS Statistics, version 25 (IBM Corporation, New York, USA).

\section{Results}

A higher proportion of women belonged to the highest social group in 2016-2017 than in 2004-2005 (Table 1). Leisure time physical activity of at least $4 \mathrm{~h} /$ week increased from almost $80 \%$ in $2004-2005$ to $>90 \%$ in
Table 2 Use of different types of analgesics among 38-and 50-year-old women in 2004-2005 and 2016-2017 in the Population Study of Women, Gothenburg

\begin{tabular}{lll}
\hline Type of analgesic & $\begin{array}{l}\text { Study year } \\
\mathbf{2 0 0 4 - 2 0 0 5} \\
\mathbf{n}(\%)\end{array}$ & $\begin{array}{l}\text { Study year } \\
\mathbf{2 0 1 6 - 2 0 1 7} \\
\mathbf{n}(\%)\end{array}$ \\
\hline $\begin{array}{l}\text { Anti-inflammatory and anti-rheumatic } \\
\text { medicines (M01) }\end{array}$ & $63(12.6)$ & $191(33.3)$ \\
Analgesics (N02) & $94(18.8)$ & $234(40.8)$ \\
Opioids (N02A) & $15(3.0)$ & $13(2.3)$ \\
Other analgesics (N02B) & $75(15.0)$ & $219(38.2)$ \\
Salicylates (N02BA) & $23(4.6)$ & $25(4.4)$ \\
Paracetamol (N02BE) & $60(12.0)$ & $203(35.4)$ \\
Anti-migraine medicines (N02C) & $14(2.8)$ & $12(2.1)$ \\
M01 + N02 & $132(26.4)$ & $335(58.5)$ \\
Total (n) & 500 & 573 \\
\hline
\end{tabular}

Table 3 Frequency of use of analgesics ( $\mathrm{M} 01+\mathrm{N} 02)$ in 38- and 50-year- old women reporting different levels of self-perceived mental stress in 2004-2005 and 2016-2017 respectively

\begin{tabular}{lcc}
\hline Stress level & \multicolumn{2}{l}{ Use of analgesics } \\
\cline { 2 - 3 } & $\begin{array}{l}\mathbf{2 0 0 4 - 2 0 0 5} \\
\mathbf{n}(\%)\end{array}$ & $\begin{array}{l}\mathbf{2 0 1 6 - 2 0 1 7} \\
\mathbf{n}(\%)\end{array}$ \\
\hline No stress (0-1) & $35(27.8)$ & $78(55.3)$ \\
Stress to some extent (2) & $25(21.4)$ & $62(56.4)$ \\
Stress to a high extent (3-5) & $69(28.3)$ & $193(60.5)$ \\
Total & $129(25.8)$ & $333(58.1)$ \\
\hline
\end{tabular}

2016-2017. Current smokers decreased from 18 to $10 \%$ during the same period. No other significant differences between the two cohorts were seen.

Table 2 shows the different types of analgesics the women used in 2004-2005 and 2016-2017. Overall, there was a higher proportion of women using analgesics in 2016-2017 compared to 2004-2005. For paracetamol, the difference in use was almost threefold between the study years.

There were 244 women reporting the highest level of stress in 2004-2005 of which $28.3 \%$ used analgesics (M01 + N02). Corresponding figures in 2016-2017 were 319 and $60.5 \%$ (Table 3 ).

In the regression analysis with analgesic use as the dependent variable, still no significant associations with perceived mental stress could be shown. In the fully adjusted model for 2004-2005 there was an association between analgesic use and pain during the last 4 weeks, as well as use of anti-acid medicines (Table 4). In 20162017, there was an association between use of analgesics and age (Table 5). 
Table 4 Logistic regression analysis of the relationship between self-perceived stress and use of analgesics in 2004-2005, adjusted for covariates in three models

\begin{tabular}{|c|c|c|c|}
\hline & $\begin{array}{l}\text { Model } 1 \\
\text { OR }(95 \% \mathrm{Cl})\end{array}$ & $\begin{array}{l}\text { Model } 2 \\
\text { OR }(95 \% \mathrm{Cl})\end{array}$ & $\begin{array}{l}\text { Model } 3 \\
\text { OR }(95 \% \mathrm{Cl})\end{array}$ \\
\hline \multicolumn{4}{|l|}{ Self-perceived mental stress } \\
\hline No stress & Ref & Ref & Ref \\
\hline Stress to some extent & $0.69(0.38-1.25)$ & $0.68(0.37-1.27)$ & $0.65(0.34-1.22)$ \\
\hline Stress to a high extent & $1.10(0.68-1.79)$ & $0.93(0.55-1.58)$ & $0.91(0.54-1.56)$ \\
\hline \multicolumn{4}{|l|}{ Age } \\
\hline 38 & Ref & Ref & Ref \\
\hline 50 & $0.99(0.96-1.03)$ & $0.98(0.94-1.01)$ & $0.98(0.94-1.02)$ \\
\hline \multicolumn{4}{|l|}{ Social group* } \\
\hline 1 & $1.62(0.85-3.11)$ & $1.97(0.98-3.96)$ & $1.85(0.90-3.78)$ \\
\hline 2 & $1.20(0.70-2.04)$ & $1.44(0.81-2.56)$ & $1.41(0.79-2.52)$ \\
\hline 3 & Ref & Ref & Ref \\
\hline Education** & $1.27(0.80-2.02)$ & $1.26(0.77-2.06)$ & $1.34(0.81-2.22)$ \\
\hline \multicolumn{4}{|l|}{ Pain during past 4 weeks } \\
\hline None & & Ref & Ref \\
\hline Very mild or mild & & $2.16(1.20-3.90)$ & $2.26(1.24-4.12)$ \\
\hline Moderate/severe/very severe & & $3.52(1.92-6.46)$ & $3.73(2.01-6.93)$ \\
\hline Use of "anti-acid medicines" & & $5.41(2.27-12.91)$ & $5.56(2.31-13.39)$ \\
\hline Use of sedatives & & $0.71(0.12-4.15)$ & $0.69(0.12-4.07)$ \\
\hline Use of hypnotics & & $0.84(0.23-3.00)$ & $0.84(0.24-3.03)$ \\
\hline Use of antidepressants & & $0.94(0.14-6.24)$ & $0.86(0.13-5.80)$ \\
\hline \multicolumn{4}{|l|}{ Smoking } \\
\hline Never/ever & & & Ref \\
\hline Currently & & & $0.77(0.43-1.40)$ \\
\hline \multicolumn{4}{|l|}{ Alcohol } \\
\hline Never & & & Ref \\
\hline Sometimes & & & $1.37(0.57-3.33)$ \\
\hline Regularly & & & $1.40(0.53-3.72)$ \\
\hline \multicolumn{4}{|l|}{ Leisure time exercise } \\
\hline At least 4 h/week & & & Ref \\
\hline Less than $4 \mathrm{~h} /$ week & & & $1.00(0.58-1.75)$ \\
\hline \multicolumn{4}{|l|}{ Amount of sleep } \\
\hline Enough sleep & & & Ref \\
\hline Not enough sleep & & & $1.12(0.71-1.76)$ \\
\hline $\begin{array}{l}\text { Goodness of fit (chi-square, degrees of freedom; } p \\
\text { value) }\end{array}$ & $3.746 ; 8 ; 0.879$ & $3.615 ; 8 ; 0.890$ & $4.438 ; 8 ; 0.816$ \\
\hline
\end{tabular}

*1. High, large-scale employers and officials of high or intermediate rank. 2. Medium, small-scale employers, officials of lower rank and foreman. 3. Low, skilled and unskilled workers

**Higher education was defined as education beyond elementary school (more than 6-7 years)

\section{Discussion}

This study used two cohorts of the same ages (38 and 50 years) at a 12-year interval to investigate whether selfperceived mental stress was associated with analgesic use. Our study did not show any associations among women between their use of analgesics and self-perceived mental stress, either in 2004-2005 or in 2016-2017, despite a more than doubled frequency of analgesic use in the later examination, i.e., from 26 to $58 \%$. Thus, we could not confirm findings concerning women, found in Koushede et al's study of an association between stress and OTC analgesic use [15]. Their further investigations showed that sense of coherence (SOC) modified the association between perceived stress and medicine use for headache in women [18]. Unfortunately, our study did not include questions about SOC.

The most relevant factor for using analgesic were having pain during the last 4 weeks, both in 2004-2005 and 
Table 5 Logistic regression analysis of the relationship between self-perceived stress and use of analgesics in 2016-2017 adjusted for covariates in three models

\begin{tabular}{|c|c|c|c|}
\hline & $\begin{array}{l}\text { Model } 1 \\
\text { OR }(95 \% \mathrm{Cl})\end{array}$ & $\begin{array}{l}\text { Model } 2 \\
\text { OR }(95 \% \mathrm{CI})\end{array}$ & $\begin{array}{l}\text { Model } 3 \\
\text { OR }(95 \% \mathrm{Cl})\end{array}$ \\
\hline \multicolumn{4}{|l|}{ Self-perceived mental stress } \\
\hline No stress & Ref & Ref & Ref \\
\hline Stress to some extent & $0.97(0.58-1.62)$ & $0.94(0.56-1.58)$ & $0.91(0.54-1.55)$ \\
\hline Stress to a high extent & $1.22(0.80-1.84)$ & $1.03(0.67-1.59)$ & $0.98(0.63-1.53)$ \\
\hline \multicolumn{4}{|l|}{ Age } \\
\hline 38 & Ref & Ref & Ref \\
\hline 50 & $0.97(0.94-0.997)$ & $0.96(0.93-0.99)$ & $0.96(0.93-0.99)$ \\
\hline \multicolumn{4}{|l|}{ Social group } \\
\hline 1 & $1.12(0.63-1.97)$ & $1.09(0.61-1.96)$ & $0.98(0.53-1.82)$ \\
\hline 2 & $1.14(0.68-1.91)$ & $1.07(0.63-1.81)$ & $1.00(0.57-1.74)$ \\
\hline 3 & Ref & Ref & Ref \\
\hline Education & $0.99(0.65-1.51)$ & $0.98(0.64-1.51)$ & $1.00(0.64-1.55)$ \\
\hline \multicolumn{4}{|l|}{ Pain during last 4 weeks } \\
\hline None & & Ref & Ref \\
\hline Very mild or mild & & $1.23(0.80-1.89)$ & $1.16(0.75-1.79)$ \\
\hline Moderate/severe/very severe & & $1.68(1.03-2.73)$ & $1.54(0.93-2.53)$ \\
\hline Use of "anti-acid medicines" & & $1.82(0.78-4.26)$ & $1.84(0.78-4.33)$ \\
\hline Use of sedatives & & $1.67(0.42-6.64)$ & $1.65(0.41-6.58)$ \\
\hline Use of hypnotics & & $1.44(0.52-4.02)$ & $1.34(0.48-3.77)$ \\
\hline Use of antidepressants & & $1.55(0.83-2.91)$ & $1.59(0.85-2.99)$ \\
\hline \multicolumn{4}{|l|}{ Smoking } \\
\hline Never/ever & & & Ref \\
\hline Currently & & & $1.00(0.54-1.85)$ \\
\hline \multicolumn{4}{|l|}{ Alcohol } \\
\hline Never & & & Ref \\
\hline Sometimes & & & $1.55(0.89-2.69)$ \\
\hline Regularly & & & $1.36(0.69-2.68)$ \\
\hline \multicolumn{4}{|l|}{ Leisure time exercise } \\
\hline At least 4 h/week & & & Ref \\
\hline Less than $4 \mathrm{~h}$ /week & & & $0.82(0.43-1.59)$ \\
\hline \multicolumn{4}{|l|}{ Amount of sleep } \\
\hline Enough sleep & & & Ref \\
\hline Not enough sleep & & & $1.31(0.90-1.90)$ \\
\hline $\begin{array}{l}\text { Goodness of fit (chi-square, degrees of freedom; } \\
\text { p-value) }\end{array}$ & $1.818 ; 7 ; 0.969$ & $9.822 ; 8 ; 0.278$ & $4.315 ; 8 ; 0.828$ \\
\hline
\end{tabular}

2016-2017 (only model 2), which could be expected. This also confirms previous Swedish research [10]. Our results could, however, not confirm associations found by Antonov et al. concerning alcohol, smoking or sleeping problems [10]. Wranker et al. showed that earlier cohorts of women used higher amounts of pain killers than the later cohorts and that men with pain used more alcohol than women with pain [29]. Our study could not confirm these findings. Cohort comparisons concerning analgesic use in women have been published earlier. A Finnish survey showed that the use was connected with occupational class, self-rated health and feelings of loneliness [30].

Previous research showed that a generally higher medicine use in women compared to men was attributed to their higher level of physical distress [31] and that college students' $(\mathrm{N}=231)$ use of OTC medications was associated with self-reported distress [32]. Another study has shown associations between perceived high job stress, measured by Karasek's job-strain model, and the use of benzodiazepines during the last month, both in women and men [33]. The use of benzodiazepines in our study 
was too low to allow worthwhile calculations to be performed.

Our study could not confirm previous research indicating that some medicine use may be a behaviour reflecting a general coping strategy to overcome daily stressors, and several explanations for this are possible. Our study used a different questionnaire for mental stress, albeit it has been evaluated [26], and the one used by Koushede also included perceived stress. We had also fewer participants than our Danish colleagues $(\mathrm{N}=4739)$ [15], which could influence the association.

Other authors have pointed out depression, oral pain and physical inactivity as measures having positive associations with self-medication [34, 35]. We did not find any associations between analgesic use and use of antidepressants or level of leisure time physical activity.

The reported usage of anti-inflammatory and antirheumatic medicines (M01) was higher in the 20162017 examination. National statistics from the Swedish Prescribed Drug Register (SPDR) show that prescriptions of M01 have decreased from 167 patients/1000 inhabitants 35-54 years old (both genders) in 2006 to 124 patients/1000 inhabitants in 2019, and from 189 patients/1000 inhabitants to 143 patients/1000 inhabitants among women during the same years [36]. This suggests that more of the women in the later examination used over-the-counter medicines, which seems reasonable considering the increased availability.

The use of paracetamol increased also in our study, from $12 \%$ in $2004-2005$ to $35 \%$ in $2016-2017$. This has been shown by other Swedish researchers, where from 2006 to 2015, the yearly prevalence of paracetamol increased, especially in young females [8]. Another study found that $70 \%$ of the population had used paracetamol in the last three months [37].

Every year recommendations and therapy advice to prescribers are presented from Drug and Therapeutics Committee in Västra Götaland Region in a booklet containing prescription guidelines. In 2004-2005, ibuprofen was recommended as the first-line medicine for short-acting pain relief and paracetamol as peripheral analgesics. In 2016-2017, naproxen became the first-line recommendation, but still paracetamol and ibuprofen are recommended [38]. Research has shown that these guidelines are followed to a high extent by primary health care doctors [39].

The re-regulation of the Swedish pharmacy market mentioned earlier has impacted on medicine use in Sweden [40]. How the use of analgesics is affected by contemporary events, such as advertising or that a medicine is withdrawn due to excessive risks, is difficult to ascertain, but there were at least two important events during the time of the study. First, there was a very active advertising with ibuprofen (Ipren) on Swedish television, which began in 1999 and continued until 2011 [41]. Second, the withdrawal of rofecoxib (Vioxx) in 2004 due to risk of cardiovascular events [42] occurred simultaneously with the collection of data for the 2004-2005 population in our study.

Among the advantages of this study are the representative selection of women, based on their date of birth as well as the cross-sectional and longitudinal designs with the same examination protocol across the years. The question concerning mental stress has been used in previous research and found to be a valid measure [26].

There are also some limitations to this study. The number of participants might have been too small to identify potential associations between self-perceived mental stress and analgesic use in women. The women in our study were 38 and 50 years old but using only younger cohorts might have given different results, since other risk perceptions have been shown by young adults when it comes to over-the-counter medicine [43].

Participants were asked about frequency of intake of analgesics and other medicines, both regarding prescription and OTC medicines by the study nurse. The questionnaire regarding medicines was unfortunately not designed in collaboration with pharmacists, which made it difficult to obtain detailed data on the use of medicines. This is something we will consider when planning for the new follow-up of PSWG in a couple of years.

\section{Conclusion}

The secular trends of higher use of analgesics among midlife women in 2016-2017 compared to 2004-2005 is in line with global findings and could be due to increased availability in Sweden of OTC medicines. The impact of mental stress on analgesic use was not confirmed. However, medicine use as a potential coping strategy is an important public health issue that needs to be further explored.

\section{Abbreviations \\ ATC code: Anatomical therapeutic chemical code; LTPA: Leisure time physical activity; OTC: Over-the-counter; prn: When needed; PSWG: Population Study of Women in Gothenburg; SPDR: Swedish prescribed drug register.}

\section{Acknowledgements}

We would like to express our special thanks of gratitude to our statistician, Valter Sundh, University of Gothenburg.

\section{Authors' contributions}

$\mathrm{GF}, \mathrm{DH}, \mathrm{CB}$ and $\mathrm{TH}$ analysed and interpreted the data. GF and $\mathrm{DH}$ were major contributors in writing the manuscript. All authors read and approved the final manuscript.

\section{Funding}

Open access funding provided by University of Gothenburg. Grant from the Swedish Research Council for Health, Working Life and Welfare-FORTE 2007-1958, grants from the Swedish State under the agreement between the 
Swedish government and the county council, the ALF agreement GBG-68771 and grants from The Health and Medical Care Committee of the Region Västra Götaland. None of the funding sources have had any roles in the design of the study or in the collection, analysis, or interpretation of data or in writing the manuscript.

\section{Availability of data and materials}

The data sets used and analysed during the current study are available from the corresponding author on reasonable request.

\section{Declarations}

\section{Ethics approval and consent to participate}

All methods were carried out in accordance with relevant guidelines and regulations. All experimental protocols were approved by the Regional Ethical Committee Gothenburg, Sweden (258-16 T853-16). Participants were informed by a personal letter about results of all examinations and whether any results required further investigation. Written informed consent for participation was obtained from the participants.

\section{Consent for publication}

Not applicable.

\section{Competing interests}

The authors declare that they have no competing interests.

\section{Author details}

${ }^{1}$ Department of Public Health and Community Medicine/Primary Health Care, School of Public Health and Community Medicine, Institute of Medicine, Sahlgrenska Academy, University of Gothenburg, PO Box 454, 40530 Gothenburg, Sweden. ${ }^{2}$ Research, Education, Development \& Innovation, Primary Health Care, Region Västra Götaland, Sweden. ${ }^{3}$ Medicine Use \& Pharmaceutical Policy, School of Public Health and Community Medicine, Institute of Medicine, University of Gothenburg, Gothenburg, Sweden.

Received: 13 February 2021 Accepted: 25 January 2022

Published online: 11 February 2022

\section{References}

1. https://www.statista.com/statistics/417687/analgesics-self-medicationmarket-sales-in-europe/. 2020. Statista, Inc. 55 Broad Street; 30th floor. New York, United States.

2. Carrasco-Garrido P, de Andres AL, Barrera VH, Jimenez-Trujillo I, Fernandez-de-Las-Penas C, Palacios-Cena D, et al. Predictive factors of self-medicated analgesic use in Spanish adults: a cross-sectional national study. BMC Pharmacol Toxicol. 2014;15:36.

3. Diener HC, Schneider R, Aicher B. Per-capita consumption of analgesics: a nine-country survey over 20 years. J Headache Pain. 2008;9:225-31.

4. The Swedish Parliament and the Government Offices. Law 2009:730. [Lag om handel med vissa receptfria läkemedel, 2009]. https://www.riksdagen. se/sv/dokument-lagar/dokument/svensk-forfattningssamling/lag-20097 30-om-handel-med-vissa-receptfria_sfs-2009-730.

5. Hedenrud T, Andersson Sundell K, Martinsson J, Hakonsen H. Attitudes towards sales and use of over-the-counter drugs in Sweden in a reregulated pharmacy market: a population-based study. Int J Pharm Pract. 2019;27:17-24

6. Carrasco-Garrido P, Jimenez-Garcia R, Barrera VH, Gil de Miguel A. Predictive factors of self-medicated drug use among the Spanish adult population. Pharmacoepidemiol Drug Saf. 2008;17:193-9.

7. Hargreave M, Andersen TV, Nielsen A, Munk C, Liaw KL, Kjaer SK. Factors associated with a continuous regular analgesic use - a population-based study of more than 45,000 Danish women and men 18-45 years of age. Pharmacoepidemiol Drug Saf. 2010;19:65-74.

8. Backryd E. Gender differences in dispensed analgesics in Sweden during 2006-2015: an observational, nationwide, whole-population study. Int J Womens Health. 2018;10:55-64.

9. Schenck-Gustafsson K. Handbook of clinical gender medicine. Basel: Karger; 2012
10. Antonov K, Isacson D. Use of analgesics in Sweden-the importance of sociodemographic factors, physical fitness, health and health-related factors, and working conditions. Soc Sci Med. 1982;1996(42):1473-81.

11. Sarganas G, Buttery AK, Zhuang W, Wolf IK, Grams D, Rosario AS, et al. Prevalence, trends, patterns and associations of analgesic use in Germany. BMC Pharmacol Toxicol. 2015;16:28.

12. Witkiewitz K, Vowles KE. Alcohol and opioid use, co-use, and chronic pain in the context of the opioid epidemic: a critical review. Alcohol Clin Exp Res. 2018;42:478-88.

13. Zgierska A, Brown RT, Zuelsdorff M, Brown D, Zhang Z, Fleming MF. Sleep and daytime sleepiness problems among patients with chronic noncancerous pain receiving long-term opioid therapy: a cross-sectional study. J Opioid Manag. 2007;3:317-27.

14. Appelberg K, Romanov K, Honkasalo ML, Koskenvuo M. The use of tranquilizers, hypnotics and analgesics among 18,592 Finnish adults: associations with recent interpersonal conflicts at work or with a spouse. J Clin Epidemiol. 1993;46:1315-22.

15. Koushede V, Holstein BE, Andersen A, Ekholm O, Hansen EH. Use of over-the-counter analgesics and perceived stress among 25-44-year olds. Pharmacoepidemiol Drug Saf. 2010;19:351-7.

16. Vowles KE, Bailey RW, McEntee ML, Pielech M, Edwards KA, Bolling LA, et al. Using analgesics for emotional modulation is associated with increased distress, depression, and risk of opioid and alcohol misuse: initial evaluation and component analysis of the reasons for analgesic use measure (RAUM). Clin J Pain. 2018;34:975-82.

17. Lissner L, Sjoberg A, Schutze M, Lapidus L, Hulthen L, Bjorkelund C. Diet, obesity and obesogenic trends in two generations of Swedish women. Eur J Nutr. 2008;47:424-31.

18. Koushede V, Holstein BE, Andersen A, Hansen EH. Stress and medicine use for headache: does sense of coherence modify the association? Eur J Public Health. 2011;21:656-61.

19. Bengtsson C, Blohme G, Hallberg L, Hallstrom T, Isaksson B, KorsanBengtsen K, et al. The study of women in Gothenburg 1968-1969-a population study. General design, purpose and sampling results. Acta Med Scand. 1973;193:311-8.

20. Bengtsson C, Ahlqwist M, Andersson K, Bjorkelund C, Lissner L, Soderstrom M. The prospective population study of women in Gothenburg, Sweden, 1968-69 to 1992-93. A 24-year follow-up study with special reference to participation, representativeness, and mortality. Scand J Prim Health Care. 1997;15:214-9.

21. Bjorkelund C, Andersson-Hange D, Andersson K, Bengtsson C, Blomstrand A, Bondyr-Carlsson D, et al. Secular trends in cardiovascular risk factors with a 36-year perspective: observations from 38- and 50-yearolds in the Population Study of Women in Gothenburg. Scand J Prim Health Care. 2008;26:140-6.

22. Rodstrom K, Weman L, Sandin L, Hange D, Bjorkelund C. Is it possible to investigate menopausal age? A comparative cross-sectional study of five cohorts between 1968 and 2017 from the Population Study of Women in Gothenburg, Swedan. Menopause. 2020;27:430-6.

23. WHO Collaborating Centre for Drug Statistics Methodology, Guidelines for ATC classification and DDD assignment 2013. Oslo, 2012.

24. Hange D, Mehlig K, Lissner L, Guo X, Bengtsson C, Skoog I, et al. Perceived mental stress in women associated with psychosomatic symptoms, but not mortality: observations from the Population Study of Women in Gothenburg, Sweden. Int J Gen Med. 2013;6:307-15.

25. Helgesson O, Cabrera C, Lapidus L, Bengtsson C, Lissner L. Selfreported stress levels predict subsequent breast cancer in a cohort of Swedish women. Eur J Cancer Prev. 2003;12:377-81.

26. Bengtsson C, Hällström T, Tibblin G. Social factors, stress experience and personality traits in women with ischaemic heart disease, compared to a population sample of women. Acta Med Scand Supp. 1973:82-92.

27. Waller M, Lissner L, Hange D, Sund V, Blomstrand A, Bjorkelund C. Socioeconomic disparities in physical activity among Swedish women and trends over time: the Population Study of Women in Gothenburg. Scand J Prim Health Care. 2018;36:363-71.

28. Hange D, Sigurdsson JA, Björkelund C, Sundh V, Bengtsson C. A 32-year longitudinal study of alcohol consumption in Swedish women: reduced risk of myocardial infarction but increased risk of cancer. Scand J Prim Health Care. 2015;33(3):153-62. 
29. Wranker LS, Elmstahl S, Ekstrom H. Pain and alcohol: a comparison of two cohorts of 60 year old women and men: findings from the Good Aging in Skane study. Scand J Pain. 2018;18:611-20.

30. Jylha M. Ten-year change in the use of medical drugs among the elderly-a longitudinal study and cohort comparison. J Clin Epidemiol. 1994;47:69-79.

31. Eggen AE. Pattern of drug use in a general population-prevalence and predicting factors: the Tromso study. Int J Epidemiol. 1994;23:1262-72.

32. Stasio MJ, Curry K, Sutton-Skinner KM, Glassman DM. Over-the-counter medication and herbal or dietary supplement use in college: dose frequency and relationship to self-reported distress. J Am Coll Health. 2008;56:535-47.

33. Pelfrene E, Vlerick P, Moreau M, Mak RP, Kornitzer M, De Backer G. Use of benzodiazepine drugs and perceived job stress in a cohort of working men and women in Belgium. Results from the BELSTRESS-study. Soc Sci Med. 2004;59:433-42.

34. Jerez-Roig J, Medeiros LF, Silva VA, Bezerra CL, Cavalcante LA, Piuvezam $\mathrm{G}$, et al. Prevalence of self-medication and associated factors in an elderly population: a systematic review. Drugs Aging. 2014;31:883-96.

35. Dale O, Borchgrevink PC, Fredheim OM, Mahic M, Romundstad P, Skurtveit S. Prevalence of use of non-prescription analgesics in the Norwegian HUNT3 population: Impact of gender, age, exercise and prescription of opioids. BMC Public Health. 2015;15:461.

36. The National Board of Health and Welfare, Sweden. Statistic about medicines. [Statistik om läkemedel]. 2020. https://sdb.socialstyrelsen.se/if_lak/ val.aspx.

37. Hedenrud T, Hakonsen H. Purchase habits, use of paracetamol, and information sources on a reregulated Swedish pharmacy market: a population-based study. Health Policy. 2017;121:35-41.

38. Committee for Medicinal Products, Region Västra Götaland, Sweden. Regional medical guidelines. [Regionala medicinska riktlinjer]. 2016-2017.

39. Axelsson MA, Spetz M, Mellen A, Wallerstedt SM. Use of and attitudes towards the prescribing guidelines booklet in primary health care doctors. BMC Clin Pharmacol. 2008;8:8.

40. Hakonsen H, Sundell KA, Martinsson J, Hedenrud T. Consumer preferences for over-the-counter drug retailers in the reregulated Swedish pharmacy market. Health Policy. 2016;120:327-33.

41. Resumé. 2019. https://www.resume.se/marknadsforing/reklam/ipren-varen-av-de-forsta-virala-filmerna-stort-misstag-att-lagga-ner/.

42. Sibbald B. Rofecoxib (Vioxx) voluntarily withdrawn from market. CMAJ. 2004;171:1027-8.

43. Hakonsen $\mathrm{H}$, Hedenrud T. A population-based study of risk perceptions of paracetamol use among Swedes-with a special focus on young adults. Pharmacoepidemiol Drug Saf. 2017;26:992-7.

\section{Publisher's Note}

Springer Nature remains neutral with regard to jurisdictional claims in published maps and institutional affiliations.

Ready to submit your research? Choose BMC and benefit from:

- fast, convenient online submission

- thorough peer review by experienced researchers in your field

- rapid publication on acceptance

- support for research data, including large and complex data types

- gold Open Access which fosters wider collaboration and increased citations

- maximum visibility for your research: over $100 \mathrm{M}$ website views per year

At BMC, research is always in progress.

Learn more biomedcentral.com/submissions 